International Journal of Automotive and Mechanical Engineering

ISSN: 2229-8649 (Print); ISSN: 2180-1606 (Online);

Volume 14, Issue 1 pp. 3872-3886 March 2017

OUniversiti Malaysia Pahang Publishing

DOI: https://doi.org/10.15282/ijame.14.1.2017.5.0315

\title{
Structural and mechanical characterisation of the chromium nitride hard coating deposited on the silicon and glass substrate
}

\author{
Hetalkumar N. Shah \\ Department of Mechanical Engineering, \\ Hansaba College of Engineering and Technology, Sidhpur, 384151 - INDIA \\ Corresponding E-mail: amihetnadiad@gmail.com
}

\begin{abstract}
Chromium Nitride $(\mathrm{CrN})$ thin films are known for their comparatively good mechanical properties. CrN was deposited on Silicon (100) and glass substrates by using DC magnetron sputtering and the influence of the partial nitrogen content and different gaseous environment on their microstructural characteristics were investigated in the present work. The CrN films were characterised with X-Ray Diffraction (XRD), Field Emission Scanning Electron Microscopy (FE-SEM), Atomic Force Microscopy (AFM) and Nanoindentation was used to characterise the structural and mechanical properties of the deposited thin film. The films showed the [200] preferred orientation at lower (at 20\%) nitrogen contents while the intensity of the peak [111] increases with the increase in the nitrogen content. The $\mathrm{Cr}_{2} \mathrm{~N}$ (220) peak was identified at a nitrogen content above $30 \%$, but for nitrogen content above $40 \%$, the $\mathrm{CrN}$ phase was observed in both films deposited on $\mathrm{Si}(100)$ and glass substrates. The preferred orientations of the $\mathrm{CrN}$ thin films are strongly influenced by the nitrogen content inside the chamber as observed in the present work. The surface roughness and deposition rate were observed in a reducing trend with the increasing $\mathrm{N}_{2}$ content and temperature from 20.31 to $2.71 \mathrm{~nm}$ and from $30.16 \mathrm{~nm} / \mathrm{min}$ to $25.66 \mathrm{~nm} / \mathrm{min}$, respectively. The hardness and modulus of pure $\mathrm{N}_{2}$ films deposited on the Si substrates were evaluated by nanoindentaion testing and indicated $31 \mathrm{GPa}$ and 250 $\mathrm{GPa}$, respectively.
\end{abstract}

Keywords: Chromium nitride; thin films; magnetron sputtering; microstructural characterizations; nanoindentation

\section{INTRODUCTION}

Metal nitrides are now commonly used in many tribological and hard protective coatings applications. For tribological and hard coating applications, the coating must possess good wear resistance, high hardness resistance and corrosion resistant properties, as reported in the literature [1-8]. To deposit the hard coating, sputtering is normally used from the available processes because of its high deposition rate, thin compound nature with controlled stoichiometry, simplicity and cost-effectiveness compared to the radio frequency (RF) system. Among the various techniques available for the deposition of $\mathrm{CrN}$ thin films, reactive magnetron sputtering could be effectively used to tailor the micro structural features of the films [9-17]. For some years, chromium nitride coatings have been gaining popularity and becoming important technological materials in the fields of cutting and forming tools, bearing and machine parts, dies and moulds. Over the past decades, the physical and mechanical properties of $\mathrm{Cr}_{x} \mathrm{~N}_{y}$ have been studied and it was 
found that it has a low coefficient of friction, high surface hardness and high toughness compared to TiN. The micro hardness in $\mathrm{CrN}$ films is insensitive to the variation in the deposition parameters due to shallower transitions in different phases [18]. Because of this reason, the $\mathrm{CrN}$ coating can now be treated as a substitute of TiN. The deposition process requires a thorough investigation of the influence of the process parameters on the microstructural characteristics in order to realise the desirable properties hitherto unachieved in the other nitrides.

The mechanical and tribological properties of the $\mathrm{CrN}$ coating deposited under different ratios of sputtering gas and reactive gases are reported in the literature [19-23]. Olaya et al. [24] noted that the RF bias voltage influenced the crystal orientation and hardness of the deposits. Levy et al. [25] studied the structural, mechanical, electronic and optical properties of transition metal nitrides $(\mathrm{CrN}, \mathrm{TiN}$, etc.) and quoted that the process parameters, e.g. the reactive gas partial pressure and the substrate bias strongly influence the film properties. Tu et al. [16] studied the phases of the $\mathrm{CrN}$ film identification indicating that at lower nitrogen contents the films exhibit $\mathrm{Cr}$ and $\mathrm{Cr}_{2} \mathrm{~N}$ phases (dual phase structure), while the $\mathrm{CrN}$ phase is observed in films with nitrogen contents higher than 58 at. \%.Z.B. Zhao et al. [26] prepared chromium nitride films by reactive DC magnetron sputtering onto multiple moving substrates and the films display a distinct phase structure, stress state and growth morphology, depending on the nitrogen flows. Also he noted that the films deposited at very low nitrogen flows show significantly refined microstructures. The macrostructural refinement, accompanied by decreased surface roughness, takes place continuously with the increasing nitrogen flow.

Nam et al. [27] studied the influence of a high deposition rate in magnetron sputtering to control the microstructures of $\mathrm{CrN}$ thin films and found that the deposition of the $\mathrm{CrN}$ compound has increased up to $90 \%$ than the pure Cr coating due to the increase in the ionization efficiency when applying a negative pulsed DC bias. Barshilia et al [28, 29] prepared $\mathrm{CrN}$ hard coatings by unbalanced magnetron pulsed DC sputtering and noted that the film hardness is affected by several factors such as packing, residual stress, stoichiometry, preferred orientation and grain size. The same researcher studied the high temperature effect on the $\mathrm{CrN}$ and $\mathrm{CrAlN}$ coating deposited by the $\mathrm{DC}$ magnetron sputtering on the mild steel and silicon substrate and noted that at around $600^{\circ} \mathrm{C}$, the $\mathrm{CrN}$ coating got oxidised while in CrAlN, no detectable oxides were formed even at $800^{\circ} \mathrm{C}$. Polcar et al. [30] applied CrN coatings on hardened steel substrates prepared by low arc deposition technologies and noted the strong dependency of the tribological parameters on temperature. The average dimension of the wear particles decreases with temperature, while the protecting layer thickness increases. Forniés et al. [19] reported that the application of bias has no effect on the phase formation but on the preferred crystal orientation and the residual tensions in $\mathrm{CrN}$ thin films deposited by $\mathrm{DC}$ magnetron sputtering. Bae et al. [31] have observed that the tribological property of the $\mathrm{CrN}$ deposited by CAIP is affected by the combined effect of textures, surface roughness, and surface hardness of the films. The residual stress affects the mechanical and tribological properties of the film. However, sputter deposited nitride films with high residual stresses affect the film-substrate interface adhesion and film thickness, while these improve the erosion resistance of the brittle materials [32, 33]. Residual stresses in thin films are due to the deposition temperature, working gas entrapment, and surface tension forces at the film/substrate interface [34]. A common way to measure the residual stresses in the thin films is based on the in situ investigation using X-Ray diffraction for measuring the deflection or curvature of the substrate. Over the last few decades, many researchers have made effort on to study the effect of the $\mathrm{N}_{2}$ gas on the microstructure and mechanical 
properties of the $\mathrm{CrN}$ thin films developed by $\mathrm{DC}$ reactive magnetron sputtering. But qualitative literatures are inadequate. At the moment, a more refined discussion / analysis is required due to unusual results in terms of phases, orientation and growth mechanism reflected on the microstructure and mechanical properties of the $\mathrm{CrN}$ film. It is essential to substantiate the role of different sputtering conditions for achieving the favoured superior micro structural characteristics in the $\mathrm{CrN}$ thin films with the enhanced final mechanical properties. Therefore, the present work has been focused to study the micro structural morphological features of the $\mathrm{CrN}$ thin films, deposited by DC-reactive magnetron sputtering, as a function of the existing sputtering conditions, such as sputtering gases, reactive gas and its proportion.

\section{METHODS AND MATERIALS}

\section{Synthesis of the CrN Films}

Chromium nitride coatings were prepared in a research based magnetron sputtering apparatus having a dual chamber equipped with standard measuring and controlling devices (pirrani gauges and mass flow controllers) to monitor the pressure and flow rates of reactive gas. The experimental setup is shown in Figure 1. All films were reactively sputtered from a pure chromium (99.95\% purity) target of $50 \mathrm{~mm}$ in diameter on the silicon and glass substrate. Prior to the deposition, the silicon substrates were cleaned in the HF solution in order to remove the oxides from the surface followed by acetone cleaning. Similarly, the glass substrates were cleaned using acetone to minimise the impurities effect during deposition. Before the sputtering and reactive gases, such as Ar and $\mathrm{N}_{2}$ allowed entering in the chamber, the sputtering chamber was evacuated to a pressure of less than $6.6 \times 10^{-4} \mathrm{~Pa}$ by a turbo molecular pump. The environment in the sputtering chamber was a mixture of $\mathrm{Ar}$ and $\mathrm{N}_{2}$ gases. The gas mixture was varied for a total flow rate of $10 \mathrm{sccm}$ during the experiments. The film was produced in two different sputtering conditions, first under different sputtering and reactive gas proportions and second under varying temperature in the pure $\mathrm{N}_{2}$ environment. The deposition condition is summarised in Table 1.

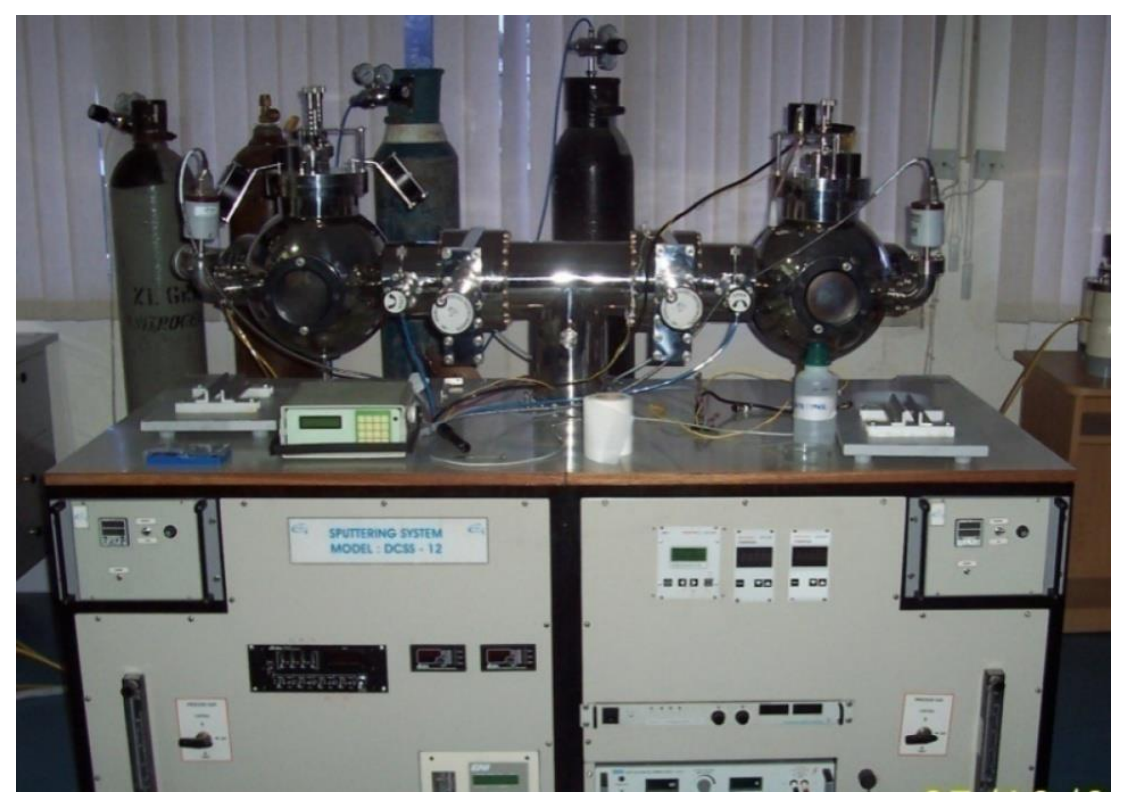

Figure 1. Experimental setup. 
Table 1. Deposition environment during the experiment.

\begin{tabular}{ll}
\hline \multicolumn{1}{c}{ Deposition Parameters } & \multicolumn{1}{c}{ Values } \\
\hline Target & Pure $\mathrm{Cr}$ \\
Substrate & $\mathrm{Si}(100)$ and Glass \\
Base Pressure & $<4 \times 10^{-6}$ Torr \\
Working Pressure & $10 \mathrm{mTorr}$ \\
Target Power Density & $75 \mathrm{~W}\left(3.82 \mathrm{~W} / \mathrm{CM}^{2}\right)$ \\
Distance between Target and & $5 \mathrm{CM}$ \\
Substrate & \\
Temperature & $300^{\circ} \mathrm{C}$ \\
Substrate Bias & $\mathrm{No}$ \\
Deposition Time & $60 \mathrm{~min}$ \\
\hline
\end{tabular}

\section{Characterisation of the CrN Films}

The $\mathrm{CrN}$ film produced on the silicon and glass substrate by reactive magnetron sputtering (RMS) was characterised using different instruments. The deposition processes for such purpose were varied with a gaseous environment and proportion of sputtering and reactive gasses in the sputtering chamber. Field Emission Scanning electron microscopy (Model: 200F, FEI-Quanta) and atomic force microscopy (NT-MDT) were used to examine the microstructure and morphology of the coatings. The phase development and other crystallographic characteristics of the coatings were examined by the XRD technique using a D8 Advance diffractometer with $\mathrm{CuK} \alpha$ radiation. The mechanical characterisation is done using nanoindentation. The hardness and Young's modulus of the coatings were determined using a CSM NHT instrument equipped with a Barkovich diamond indenter and considering the Oliver \& Pharr method. The maximum indentation load applied was $15 \mathrm{mN}$ for a $\mathrm{CrN}$ film deposited at different Ar: $\mathrm{N}_{2}$ content values, while the indentation depth was restricted and set to $130 \mathrm{~nm}$ to eliminate the influence of the substrate properties effect for a film deposited in pure $\mathrm{N}_{2}$ and in a different gas environment. The phases and preferred orientation of $\mathrm{CrN}$ thin films in the as deposited condition was characterised by X-Ray Diffraction. The X-ray was generated using the $\mathrm{Cu}$ anode by applying voltage and current with values set to a $40 \mathrm{Kv}$ and $30 \mathrm{~mA}$, respectively. The scans were collected over a $2 \theta$ range from $30^{\circ}$ to $100^{\circ}$ to find out the possible changes in the texture orientation. The scan rate was $1 \% \mathrm{~min}$ with a step size of $0.05^{\circ}$. The grain size of the films was calculated using the Scherrer formula [35] and the basis of the surface morphology derived from an AFM with the aid of software calculation.

\section{RESULTS AND DISCUSSION}

\section{Effect of the $\mathrm{N}_{2}$ Content}

The deposition rate of the $\mathrm{CrN}$ coatings with an increasing nitrogen content is shown in Figure 2. The results showed that initially at $20 \% \mathrm{~N}_{2}$ content, the deposition rate was found to be 73 and $71 \mathrm{~nm}$ for $\mathrm{Si}(100)$ and for the glass substrates, respectively which is reduced to 54 and $59 \mathrm{~nm}$, respectively when increasing the nitrogen content (60:40) in the chamber. However, the deposition rate of the coatings produced on $\mathrm{Si}(100)$ and glass was almost the same, up to a 70:30 argon nitrogen mixture. With the film on the $\mathrm{Si}(100)$ substrates, the coating was deposited at a rate of $73 \mathrm{~nm} / \mathrm{min}$ initially and then dropped to $35 \mathrm{~nm} / \mathrm{min}$ at a 50:50 argon nitrogen mixer. The reduction in the deposition rate indicates that with an increased nitrogen content there is an additional reaction with the $\mathrm{Cr}$ target 
and formation of the nitride layer at the outer surface of the target. Also, the insertion of nitrogen in the chamber involves non-uniform stresses and the formation of different CrNx phases. The dominating peak or the main peak will broaden with a small shift to the higher or lower angle.

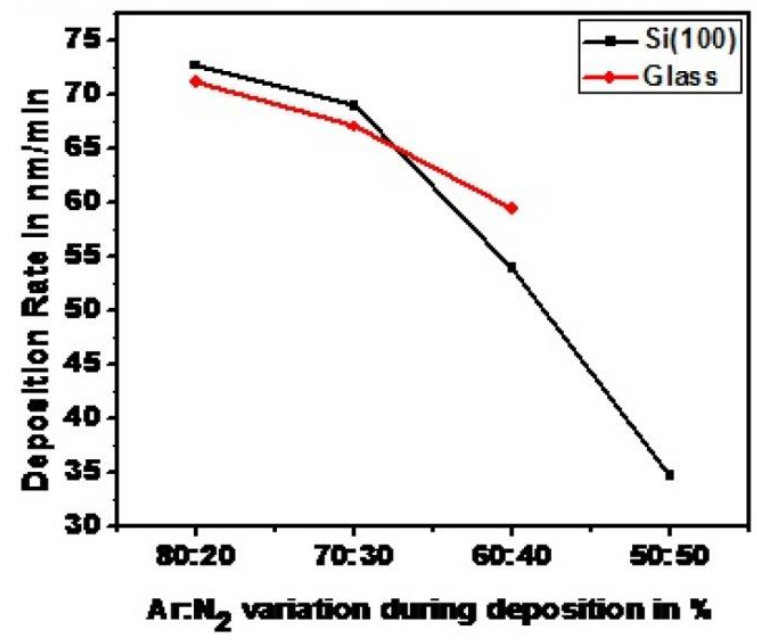

Figure 2. Deposition rate of the CrN coatings deposited on $\mathrm{Si}$ (100) and glass substrates with increasing nitrogen content.

The diameter of the columnar grains was measured by XRD and atomic force microscopy and the results are shown in Figure 3. It was found that at a low nitrogen content of $20 \%$, nanostructured coatings with an average columnar grain diameter of 16 and $71 \mathrm{~nm}$ were measured by XRD and AFM respectively, developed on the $\mathrm{Si}(100)$ substrate and reduced at a regular interval when increasing the $\mathrm{N}_{2}$ content in the sputtering chamber due to a lower fewer collisions with the gas particles in the chamber. The sputtered $\mathrm{Cr}$ atoms would also undergo fewer collisions leading to a low probability of agglomeration and growth even before arriving at the substrate [36]. However, there is a variation in grain size measured by XRD and AFM because of the fact that the XRD gave the average mean crystallite size while FESEM showed an agglomeration of the particles.

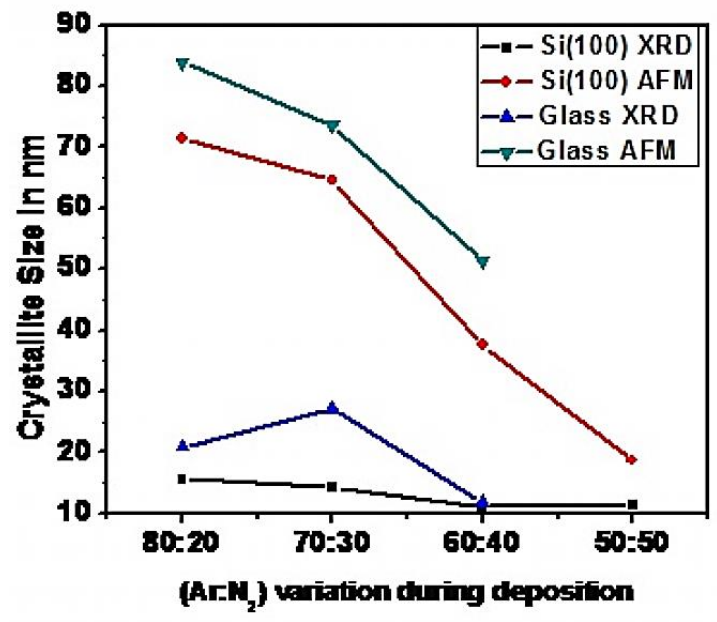

Figure 3. Grain Size of the CrN films deposited on various substrates measured with $\mathrm{XRD}$ and AFM. 
The effect of different proportions of reactive gas $\left(\mathrm{N}_{2}\right)$ with the sputtering gas $(\mathrm{Ar})$ and the effect of different gaseous environments on the microstructural characteristics of the $\mathrm{CrN}$ film deposited on $\mathrm{Si}(100)$ and glass substrates are shown using XRD graphs in Figures 4-5. It clearly shows that the orientation is changing from a (200) to a (111) orientation in the film deposited on $\mathrm{Si}(100)$ and glass substrates with an increase in the nitrogen content in the sputtering chamber. The films deposited using the lower content of $\mathrm{N}_{2}$ gas had a dual structure in which the most dominating peak orientation is (200) with a relatively weak (111) peak orientation, indicating a textured film. The (111) orientation is very low or almost negligible at a $20 \% \mathrm{~N}_{2}$ concentration in the case of the film deposited on the glass substrate. We observed that the texture coefficient $\mathrm{I}_{111}$ is relatively much higher in the film deposited on the glass substrate than on the $\operatorname{Si}(100)$ substrates at a concentration of $40 \% \mathrm{~N}_{2}$; this may be due to the dominating nature of the strain energy over the free surface energy in the film during deposition which favours the (111) orientation growth. The peak intensity (111) is increased with the increase in the nitrogen content in the gaseous environment in the chamber. The result of the preferred orientation is moderately different than the results of E. Forniés [19] in which the preferred (200) orientation is identified at a higher $\mathrm{N}_{2}$ content (between 5\% and 30\%). Also the peak (200) is broadened with the increase in the nitrogen content giving the indication of a reduction in the mean crystallographic domain size or particle size and it is confirmed by the FESEM and AFM as shown in Figures 6-7 in both $\mathrm{Si}(100)$ and glass substrates.

(a)

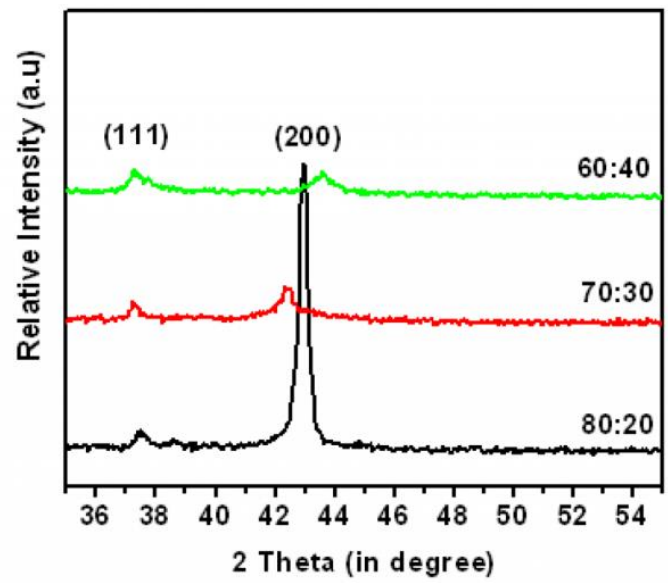

(b)

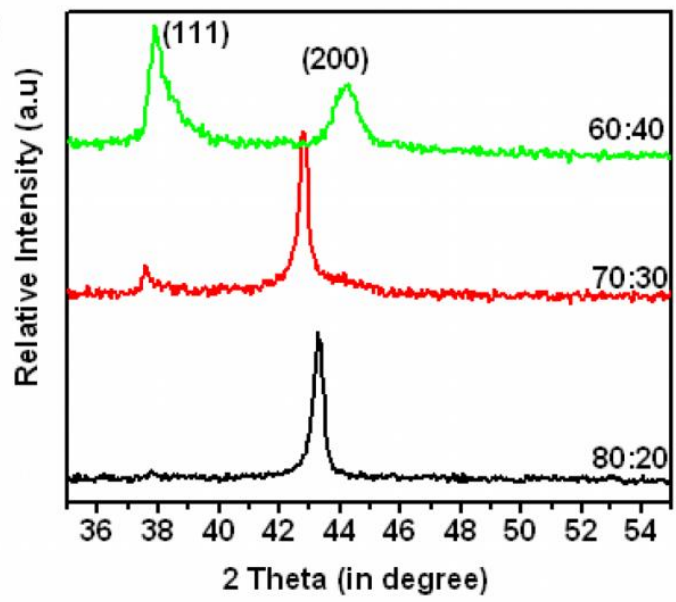

Figure 4. XRD spectrum of the $\mathrm{CrN}$ film deposited at different $\mathrm{Ar}+\mathrm{N}_{2}$ gas ratio: a) $\mathrm{Si}$ (100) substrate b) Glass substrate. 

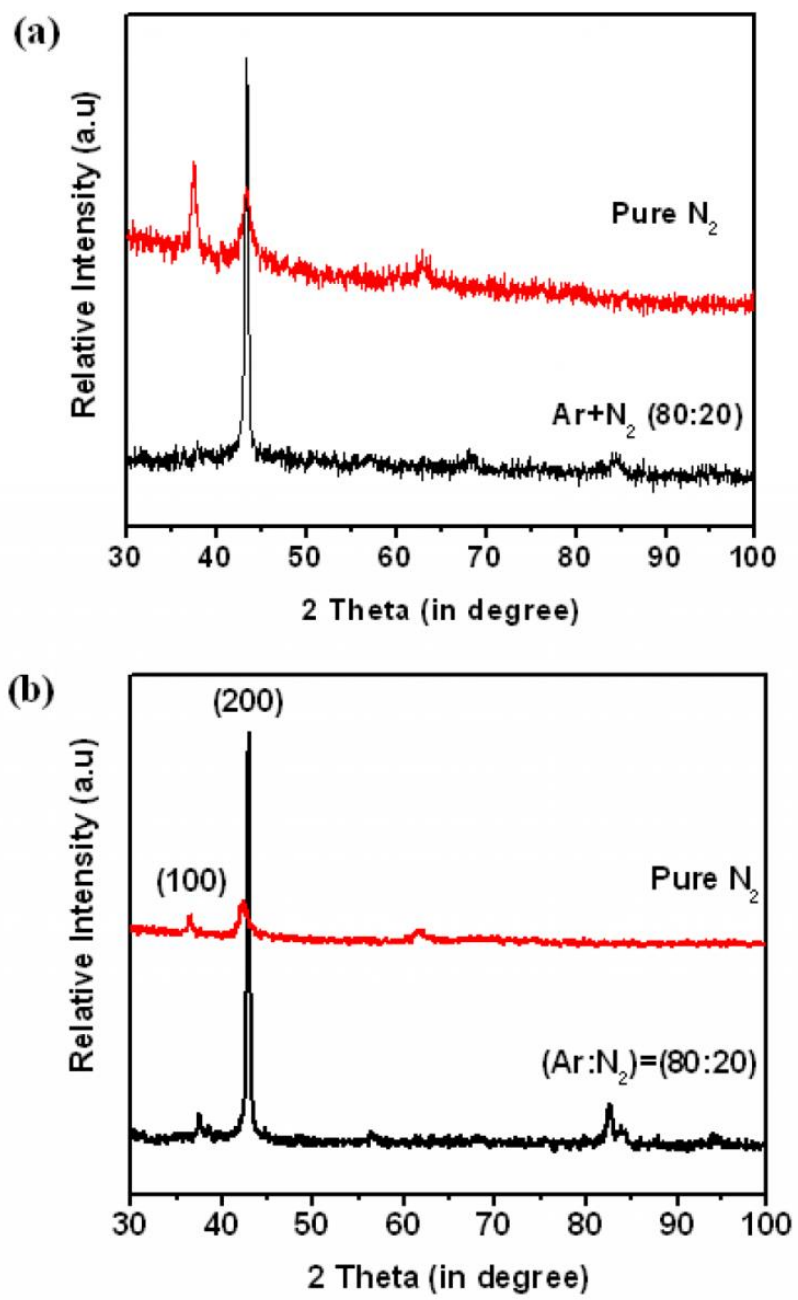

Figure 5. XRD spectrum of the $\mathrm{CrN}$ film deposited in the different gas environments a) on the glass substrate, b) on the $\mathrm{Si}(100)$ substrate.

The effect of different Ar: $\mathrm{N}_{2}$ compositions on the existing mechanical properties (hardness and modulus) are explained below. In the case of a $20 \% \mathrm{~N}_{2}$ content in the chamber during deposition, the film has a $\mathrm{Cr}+\mathrm{CrN}$ phase having a predominant (200) state orientation with a columnar structure, which possess $13.5 \mathrm{GPa}$ in nanohardness. The lower hardness may be due to the presence of $\mathrm{Cr}$ which possesses lower hardness. With the increase in the $\mathrm{N}_{2}$ content in the chamber, the $\mathrm{Cr}_{2} \mathrm{~N}$ phase is introduced and a mixture of $\mathrm{CrN}+\mathrm{Cr}_{2} \mathrm{~N}$ is formed at $30 \%$. The hardness is comparatively increased due to the introduction of the $\mathrm{Cr}_{2} \mathrm{~N}$ phase in the film. At a $\mathrm{N}_{2}$ content of $40 \%$, dual structure $\mathrm{CrN}+\mathrm{Cr}_{2} \mathrm{~N}$ films have formed in which the $\mathrm{Cr}_{2} \mathrm{~N}$ phase is more pronounced, which possess an increased hardness of $18.63 \mathrm{GPa}$ due to the presence of a hexagonal crystal structure and strong covalent bonding in the $\mathrm{Cr}_{2} \mathrm{~N}$ phase present in the films. The lower hardness of the $\mathrm{CrN}$ films as compared to the $\mathrm{Cr}_{2} \mathrm{~N}$ films may be due to their higher degree of ionicity of the bonding [2]. Here we noted that the hardness is more influenced by the film morphology and texture. A further increase in the $\mathrm{N}_{2}$ content may lead to increased amorphosization in the film. Bertrand et al. [37] noted that the hardness is affected by a number of factors, including the stresses developed, cryatallographic orientation and direction, grain size and density. 

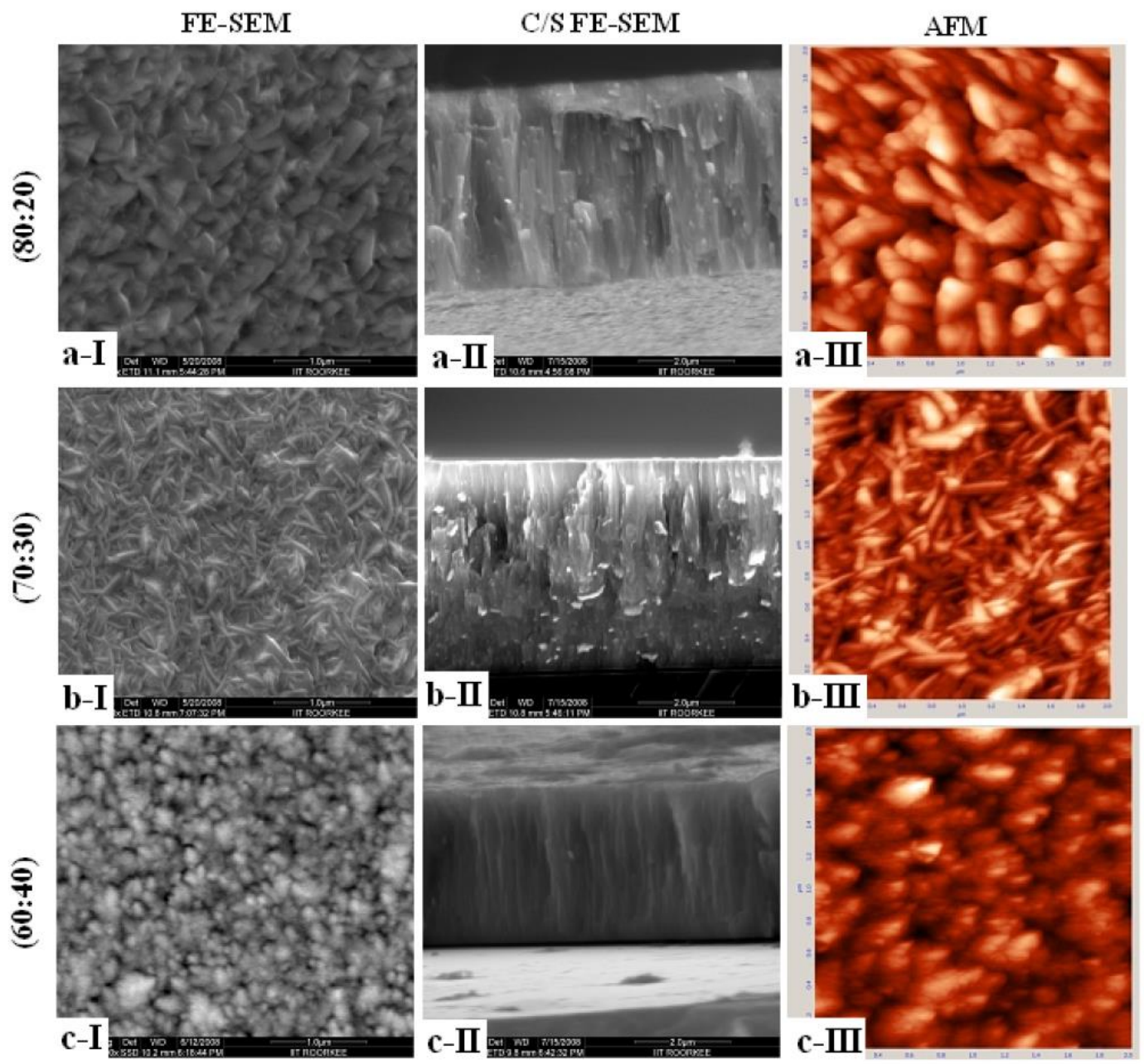

Figure 6. I) FE-SEM, II) C/S FE-SEM and III) AFM of the CrN thin film deposited on the $\mathrm{Si}(100)$ substrate a) $\left(\operatorname{Ar}: \mathrm{N}_{2}\right)=(80: 20)$, b) $(\operatorname{Ar}: \mathrm{N} 2)=(70: 30)$, c) $\left(\operatorname{Ar}: \mathrm{N}_{2}\right)=(60: 40)$.

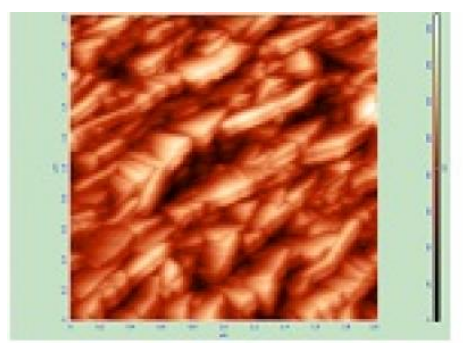

$80: 20$

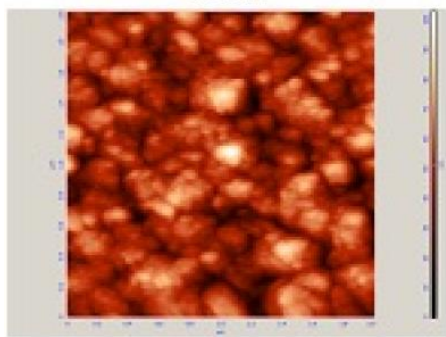

$60: 40$

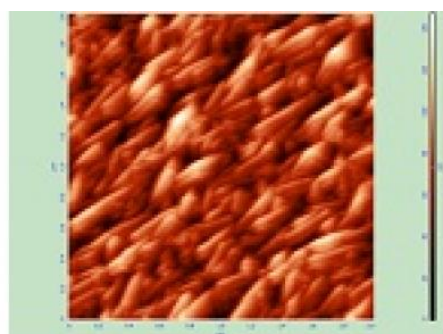

70:30

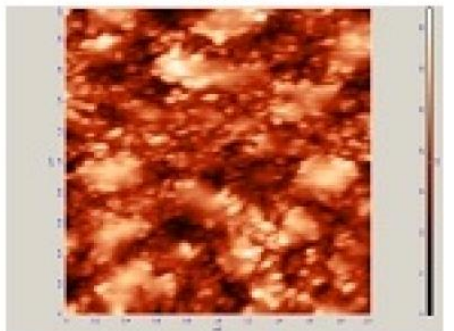

Pure $\mathrm{N}_{2}$

Figure 7. AFM of CrN thin film deposited on the glass substrate a) $\left.\left(\operatorname{Ar}: \mathrm{N}_{2}\right)=(80: 20), \mathrm{b}\right)$ $\left.\left.\left(\operatorname{Ar}: \mathrm{N}_{2}\right)=(70: 30), c\right)\left(\operatorname{Ar}: \mathrm{N}_{2}\right)=(60: 40), \mathrm{d}\right)$ Pure $\mathrm{N}_{2}$ 


\section{Effect of Different Sputtering Gases}

Also the chromium nitride film deposited on different substrates with different gas proportions like $80 \% \mathrm{Ar}+20 \% \mathrm{~N}_{2}$ and $100 \% \mathrm{~N}_{2}$ is referred to as $\mathrm{Ar}+\mathrm{N}_{2}$ and Pure $\mathrm{N}_{2}$, respectively. Figure 8 shows the cross section images of chromium nitride with different gas mixtures in which the deposition rate was observed as $4.37 \mu \mathrm{m}$ and $1.73 \mu \mathrm{m}$ for Ar: $\mathrm{N}_{2}$ and Pure $\mathrm{N}_{2}$, respectively. In the pure $\mathrm{N}_{2}$ deposition, which is a mainly nitride mode of deposition, the deposition rate is very low compared to films deposited in a mixture of $\mathrm{Ar}+\mathrm{N}_{2}$, mainly in a metallic mode of deposition [38, 39].
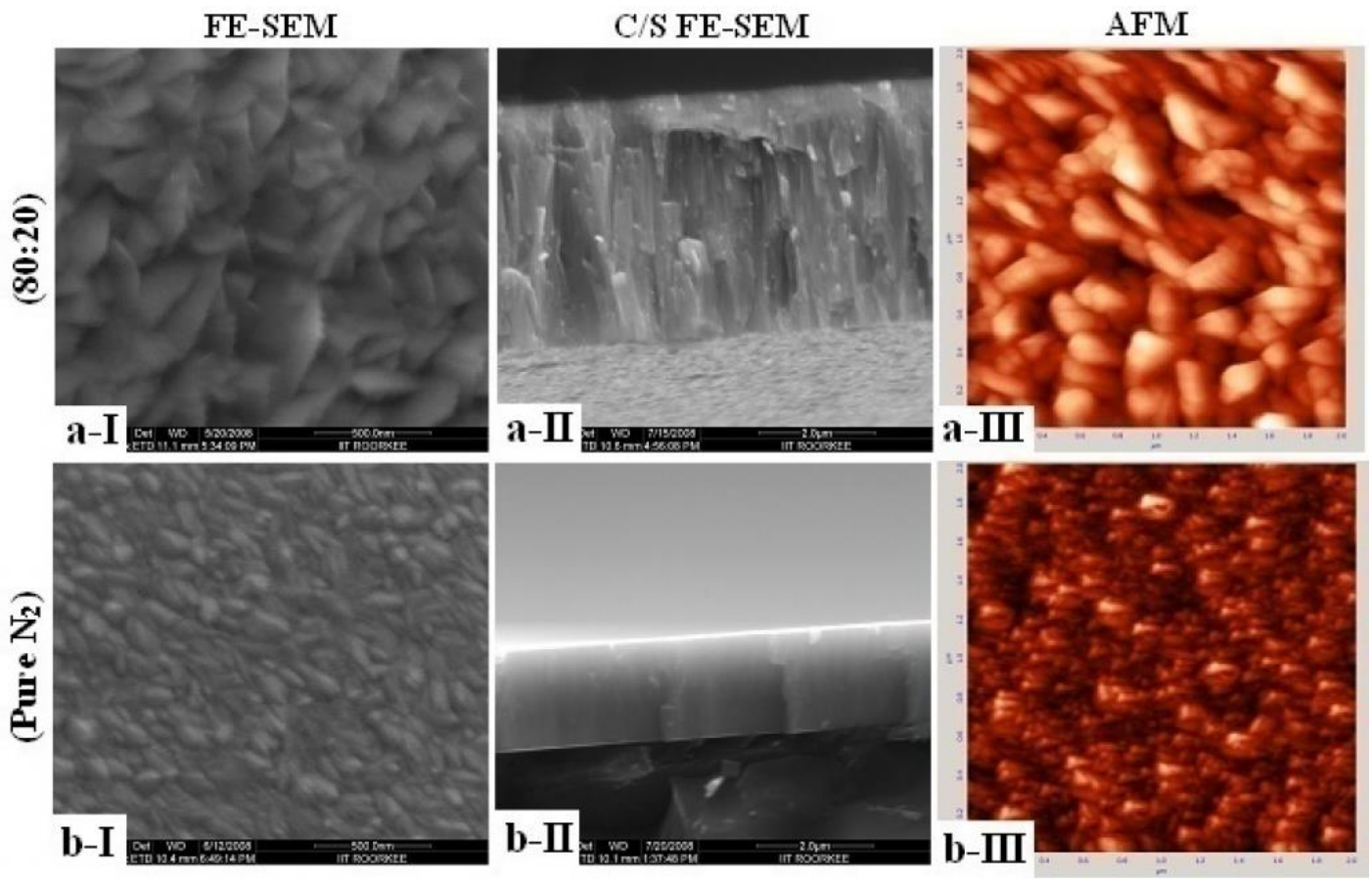

Figure 8. (I) FE-SEM, (II) C/S FE-SEM and (III) AFM of the CrN thin film deposited on the $\mathrm{Si}(100)$ substrate using different gas mixtures a) $\left(\mathrm{Ar}_{\mathrm{N}} \mathrm{N}_{2}\right)=(80: 20)$, b) Pure $\mathrm{N}_{2}$.

The particle size under different sputtering conditions was measured and found to be $14.05 \mathrm{~nm}$ and $10.83 \mathrm{~nm}$ for the film deposited on $\mathrm{Si}(100)$. The differences in particle size can be explained by the relationship of the mean free path, $\lambda(\mathrm{cm})$, with the molecular diameter of the sputtering gas as indicated Equation 1 [40, 41].

$$
\lambda=2.330 \times 10^{-20} \frac{T}{\left(P \delta_{m}^{2}\right)}
$$

where $T$ (in ${ }^{\circ} \mathrm{K}$ ) is the temperature, $P$ (in Torr) is the pressure and $\delta \mathrm{m}$ (in $\mathrm{cm}$ ) is the molecular diameter. According to the above equation, the particle size must be the largest in the case of the argon-nitrogen gas mixture as the atomic diameter of argon is the largest among those of the two gaseous environments [42, 43]. In this research, the particle size calculated by XRD and AFM conforms to the expectations from the above equation. The surface roughness (RMS) was measured and found to be 20.47 and 3.44 for $\mathrm{Ar}: \mathrm{N}_{2}$ and Pure $\mathrm{N}_{2}$, respectively. 
Table 2. Effect of the $\mathrm{N}_{2}$ concentration in the chamber during deposition on the $\mathrm{Si}$ (100) and glass substrates.

\begin{tabular}{|c|c|c|c|c|c|c|c|}
\hline$\left(\mathrm{Ar}+\mathrm{N}_{2}\right)$ & \multirow{2}{*}{\multicolumn{3}{|c|}{$\begin{array}{l}\text { Crystallite Size XRD } \\
\text { (in } \mathrm{nm} \text { ) }\end{array}$}} & \multirow{4}{*}{$\begin{array}{c}\text { Crystallite } \\
\text { Size AFM } \\
\text { (in } \mathrm{nm} \text { ) }\end{array}$} & \multirow{4}{*}{$\begin{array}{c}\text { Average } \\
\text { Roughness } \\
\text { AFM (in } \\
\text { nm) }\end{array}$} & \multirow{4}{*}{$\begin{array}{c}\text { Film } \\
\text { Thickness } \\
\text { (in } \mu \mathrm{m} \text { ) }\end{array}$} & \multirow{4}{*}{$\begin{array}{c}\text { Deposition } \\
\text { Rate (in } \\
\mathrm{nm} / \mathrm{min} \text { ) }\end{array}$} \\
\hline Variation & & & & & & & \\
\hline during & $\mathrm{D}_{111}$ & $\mathrm{D}_{200}$ & $\mathrm{D}_{\mathrm{Av}}$ & & & & \\
\hline Deposition & & & & & & & \\
\hline \multicolumn{8}{|c|}{ Variation in $\mathrm{N}_{2}$ Concentration (Si Substrate) } \\
\hline$(80: 20)$ & 14.05 & 17.15 & 15.60 & 71.33 & 16.63 & 4.36 & 72.66 \\
\hline$(70: 30)$ & 14.04 & 14.27 & 14.15 & 64.50 & 14.79 & 4.14 & 69.0 \\
\hline$(60: 40)$ & 12.03 & 10.06 & 11.04 & 37.58 & 7.77 & 3.23 & 53.83 \\
\hline$(50: 50)$ & 10.46 & 12.26 & 11.36 & 18.69 & 3.71 & 2.08 & 34.66 \\
\hline Pure $\mathrm{N}_{2}$ & 26.59 & 10.83 & 18.71 & 14.45 & 2.71 & -- & -- \\
\hline \multicolumn{8}{|c|}{ Variation in $\mathrm{N}_{2}$ Concentration (Glass Substrate) } \\
\hline$(80: 20)$ & -- & 20.89 & 20.89 & 83.86 & 20.31 & 4.27 & 71.16 \\
\hline$(70: 30)$ & 29.64 & 24.66 & 27.15 & 73.54 & 17.18 & 4.02 & 67.0 \\
\hline$(60: 40)$ & 14.38 & 9.08 & 11.73 & 51.44 & 12.89 & 3.56 & 59.33 \\
\hline Pure $\mathrm{N}_{2}$ & 13.3 & 9.05 & 11.19 & 18.66 & 4.83 & -- & -- \\
\hline
\end{tabular}

Effect of Substrate Materials (In Terms of XRD and Surface and Strain Energy)

It was established that the substrate material also has a strong influence on the phase constituents and the orientation of that phase. The deposited hard film, as the name implies, must have a higher value of mechanical properties such as hardness, wear resistance and tribological properties. The mechanical, wear and tribological properties of the film are affected by the phases and orientations of the films as reported in the literature $[38,44]$. So the study of the preferred orientation of the $\mathrm{CrN}$ thin films is also important from an application point of view. Figure 4 shows the XRD patterns as a function of the nitrogen content deposited on each of the substrates used and Figure 5 shows the XRD patterns as a function of the different sputtering gases used. The CrN films deposited on $\mathrm{Si}(100)$ exhibited a highly preferred crystalline-structure (200) plane but the $\mathrm{CrN}$ film deposited on glass exhibited a randomly oriented and comparatively dense structure with a mixed preferred orientation of (200) and (111) [45]. It is reported that for a small film thickness and low substrate temperatures the growth of the $\mathrm{CrN}$ film is controlled by the surface energy while for a comparatively high film thickness at a high temperature, the growth of the $\mathrm{CrN}$ film is controlled by the strain energy [46]. In this experimental result, the (200) plane has a preferred orientation relative to the $\mathrm{Si}(100)$ substrate at a lower $\mathrm{N}_{2}$ concentration and higher thickness due to the dominating nature of the strain energy over the surface energy while in the case of a relatively higher $\mathrm{N}_{2}$ concentration and small thickness, the (111) plane has a preferred orientation because of the surface energy dominating over the strain energy [47]. Similarly, the CrN film deposited on the Si (100) and glass substrates with different gaseous environments and results were analysed. The results are tabulated in Table 2 . The analysis revealed that at Ar: $\mathrm{N}_{2}$ (80:20), the particle size was found to be $16 \mathrm{~nm}$ and $71 \mathrm{~nm}$ by the XRD and AFM respectively, while the deposition in pure $\mathrm{N}_{2}$ was found to be $19 \mathrm{~nm}$ and $14 \mathrm{~nm}$ by the $\mathrm{XRD}$ and AFM, respectively. However, the average surface roughness was reduced from $16.63 \mathrm{~nm}$ to $2.71 \mathrm{~nm}$ and 20.31 to $4.83 \mathrm{~nm}$ for the film deposited on Si (100) and glass substrate, respectively. 

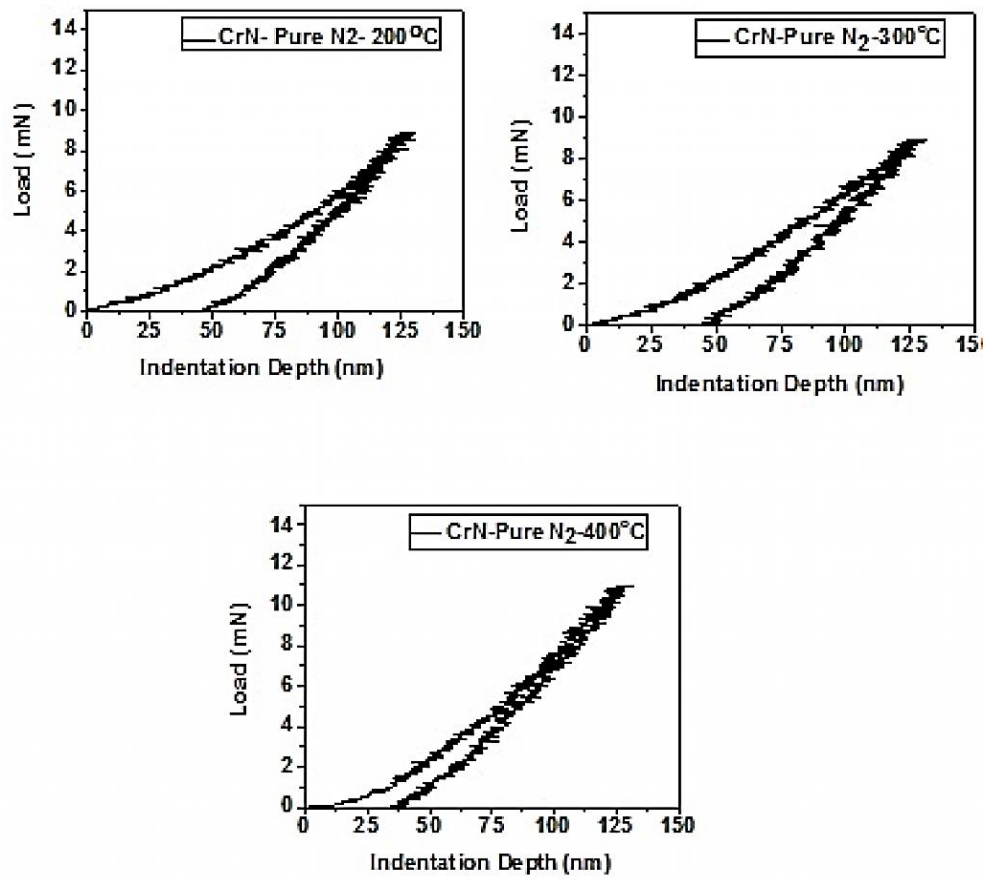

Figure 9. Load displacement curves for different temperature values.

\section{Effect of the Substrate Temperature}

The $\mathrm{CrN}$ film deposited in a pure $\mathrm{N}_{2}$ environment at different temperature was analysed and the substrate temperature effect on the microstructure of the $\mathrm{CrN}$ film can be discussed. The structure was changed in line with the increase in temperature due to the plasma state between the target and substrate changing as the substrate temperature increased. At higher substrate temperatures, the temperature of the target surface increased due to thermal radiation. The deposition rate of the films decreased from 30.16 $\mathrm{nm} / \mathrm{min}$ to $25.66 \mathrm{~nm} / \mathrm{min}$ with an increase of the substrate temperature from $200^{\circ} \mathrm{C}$ to $400^{\circ} \mathrm{C}$. The deposition in a pure nitrogen environment leads to a low deposition rate owing to the nitride mode. The observed lower deposition rate at a higher substrate temperature, despite the higher adatom mobility during the nitride mode of deposition, is probably due to an increased collision between the sputtered particle and the gas atom, leading to a reduced number of atoms to arrive on the substrate [48]. The lower deposition rates at higher substrate temperatures may be due to the balance between the number of atoms arriving on the substrate surface and the atoms leaving from the substrate surface by further evaporation.

The hardness and modulus of the $\mathrm{CrN}$ films deposited in pure $\mathrm{N}_{2}$ with variation in temperature are analysed. It can be observed that under experimental temperatures below $673 \mathrm{~K}$, the hardness increases with the increasing substrate temperature in a pure $\mathrm{N}_{2}$ environment [3]. The load displacement curves for different temperature values are shown in Figure 8. The highest value of hardness and modulus were observed at approximately $31 \mathrm{GPa}$ and $250 \mathrm{GPa}$, respectively. The increased hardness can be attributed to the nitrogen content in the film, highly dances columnar structure and comparatively lower surface roughness observed in the present experiment [40]. 


\section{CONCLUSIONS}

The series of $\mathrm{CrN}$ films are deposited on the $\mathrm{Si}(100)$ and glass substrates to study the influence of the $\mathrm{N}_{2}$ proportion and different gaseous environments in the chamber. The following points were found:

1) The orientation is changing from a (200) to a (111) orientation in the film deposited on the $\mathrm{Si}(100)$ and glass substrates with an increase in the nitrogen content in the sputtering chamber. Also we observed that the texture coefficient $\mathrm{I}_{111}$ is relatively much higher in the film deposited on the glass substrate than on the $\mathrm{Si}(100)$ substrates at $40 \% \mathrm{~N}_{2}$ concentration, which may be due to the dominating nature of strain energy over the free surface energy in the film during deposition which favours the (111) orientation growth.

2) The particle size was decreasing with the increase in the nitrogen content as opposed to the argon content in the sputtering chamber due to the lower atomic diameter of nitrogen compared to argon. This resulted in higher MFP, causing a reduced number of collisions with the gas particles in the chamber. The sputtered $\mathrm{Cr}$ atoms would also undergo fewer collisions leading to a low probability of agglomeration and growth even before arriving at the substrate.

3) The surface roughness of the $\mathrm{CrN}$ film decreases with the increasing substrate temperature.

4) The mixture of different gases affects the surface morphology, particle size and mechanical properties. The film deposited in a pure $\mathrm{N}_{2}$ (nitride mode of deposition) environment gives a comparatively smaller particle size. Also the deposition rate was reduced.

5) The final structure produced depends not only on the process parameters and gases but also on the substrates materials.

\section{ACKNOWLEDGEMENT}

The authors would like to thank Dr. R Chandra for providing the experimental facilities for the present work at Nano-Science laboratory, Institute Instrumentation Center, IIT Roorkee.

\section{REFERENCES}

[1] Safi I. Recent aspects concerning DC reactive magnetron sputtering of thin films: a review. Surface and Coatings Technology. 2000;127:203-18.

[2] Hones P, Sanjines R, Levy F. Characterization of sputter-deposited chromium nitride thin films for hard coatings. Surface and Coatings Technology. 1997;94:398-402.

[3] Wan S, Pu J, Li D, Zhang Ga, Zhang B, Tieu AK. Tribological performance of $\mathrm{CrN}$ and CrN/GLC coated components for automotive engine applications. Journal of Alloys and Compounds. 2017;695:433-42.

[4] Shah HN, Jayaganthan R, Kaur D, Chandra R. Influence of sputtering parameters and nitrogen on the microstructure of chromium nitride thin films deposited on steel substrate by direct-current reactive magnetron sputtering. Thin Solid Films. 2010;518:5762-8. 
[5] Moniruzzaman M, Rakib MM, Matin FT. Cr-Ni Alloy Electrodeposition and Comparison with Conventional Pure Cr Coating Technique. International Journal of Automotive and Mechanical Engineering. 2012;6:692-700.

[6] Moniruzzaman M, Roy S. Effect of $\mathrm{pH}$ on electroless Ni-P coating of conductive and non-conductive materials. International Journal of Automotive and Mechanical Engineering. 2011;4:481-9.

[7] Ahmad R, Ajer MR. Investigation of Epoxy Powder Coated Galvanized Steel Substrate through Electrostatic Powder Coating System. International Journal of Automotive and Mechanical Engineering. 2015;11:2622-38.

[8] Jesbains K, Kuwano N, Jamaludin KR, Miyake H, Hiramatsu K, Suzuki S, et al. Reduction of dislocation density of aluminium nitride buffer layer grown on sapphire substrate. Journal of Mechanical Engineering and Sciences. 2016;10:1908-16.

[9] Schlögl M, Mayer B, Paulitsch J, Mayrhofer P. Influence of CrN and AlN layer thicknesses on structure and mechanical properties of CrN/AlN superlattices. Thin Solid Films. 2013;545:375-9.

[10] Chen Q, Cao Y, Xie Z, Chen T, Wan Y, Wang H, et al. Tribocorrosion behaviors of CrN coating in $3.5 \mathrm{wt} \% \mathrm{NaCl}$ solution. Thin Solid Films. 2017;622:41-7.

[11] Aubert A, Gillet R, Gaucher A, Terrat J. Hard chrome coatings deposited by physical vapour deposition. Thin Solid Films. 1983;108:165-72.

[12] Aubert A, Danroc J, Gaucher A, Terrat J. Hard chrome and molybdenum coatings produced by physical vapour deposition. Thin Solid Films. 1985;126:61-7.

[13] Gautier C, Moussaoui H, Elstner F, Machet J. Comparative study of mechanical and structural properties of $\mathrm{CrN}$ films deposited by dc magnetron sputtering and vacuum arc evaporation. Surface and Coatings Technology. 1996;86:254-62.

[14] Rebholz C, Ziegele H, Leyland A, Matthews A. Structure, mechanical and tribological properties of nitrogen-containing chromium coatings prepared by reactive magnetron sputtering. Surface and Coatings Technology. 1999;115:2229.

[15] He XM, Baker N, Kehler B, Walter K, Nastasi M, Nakamura Y. Structure, hardness, and tribological properties of reactive magnetron sputtered chromium nitride films. Journal of Vacuum Science \& Technology A: Vacuum, Surfaces, and Films. 2000;18:30-6.

[16] Tu JN, Duh JG, Tsai SY. Morphology, mechanical properties, and oxidation behavior of reactively sputtered $\mathrm{Cr}-\mathrm{N}$ films. Surface and Coatings Technology. 2000;133:181-5.

[17] Ou Y, Lin J, Che H, Sproul W, Moore J, Lei M. Mechanical and tribological properties of $\mathrm{CrN} / \mathrm{TiN}$ multilayer coatings deposited by pulsed dc magnetron sputtering. Surface and Coatings Technology. 2015;276:152-9.

[18] Meunier C, Vives S, Bertrand G. X-ray diffractometry analysis of rf-magnetronsputtered chromium/chromium nitride coatings. Surface and Coatings Technology. 1998;107:149-58.

[19] Forniés E, Galindo RE, Sánchez O, Albella J. Growth of CrN x films by DC reactive magnetron sputtering at constant $\mathrm{N}_{2} / \mathrm{Ar}$ gas flow. Surface and Coatings Technology. 2006;200:6047-53.

[20] Van Essen P, Hoy R, Kamminga J-D, Ehiasarian A, Janssen G. Scratch resistance and wear of CrN x coatings. Surface and Coatings Technology. 2006;200:3496502. 
[21] Han Z, Tian J, Lai Q, Yu X, Li G. Effect of $\mathrm{N}_{2}$ partial pressure on the microstructure and mechanical properties of magnetron sputtered $\mathrm{CrN} \times$ films. Surface and Coatings Technology. 2003;162:189-93.

[22] Maleque MA, Radhi M, Rahman MM. Wear study of Mg-SiCp reinforcement aluminium metal matrix composite. Journal of Mechanical Engineering and Sciences. 2016;10:1758-64.

[23] Alias AA, Kinoshita H, Nishina Y, Fujii M. Dependence of pH level on tribological effect of graphene oxide as an additive in water lubrication. International Journal of Automotive and Mechanical Engineering. 2016;13:31506.

[24] Olaya J, Rodil S, Muhl S, Sánchez E. Comparative study of chromium nitride coatings deposited by unbalanced and balanced magnetron sputtering. Thin solid films. 2005;474:119-26.

[25] Lévy F, Hones P, Schmid P, Sanjinés R, Diserens M, Wiemer C. Electronic states and mechanical properties in transition metal nitrides. Surface and coatings technology. 1999;120:284-90.

[26] Zhao Z, Rek Z, Yalisove S, Bilello J. Nanostructured chromium nitride films with a valley of residual stress. Thin Solid Films. 2005;472:96-104.

[27] Nam KH, Jung MJ, Han JG. A study on the high rate deposition of CrN x films with controlled microstructure by magnetron sputtering. Surface and Coatings Technology. 2000;131:222-7.

[28] Barshilia HC, Rajam K. Reactive sputtering of hard nitride coatings using asymmetric-bipolar pulsed DC generator. Surface and Coatings Technology. 2006;201:1827-35.

[29] Barshilia HC, Selvakumar N, Deepthi B, Rajam K. A comparative study of reactive direct current magnetron sputtered $\mathrm{CrAlN}$ and $\mathrm{CrN}$ coatings. Surface and Coatings Technology. 2006;201:2193-201.

[30] Polcar T, Parreira N, Novák R. Friction and wear behaviour of $\mathrm{CrN}$ coating at temperatures up to 500 C. Surface and Coatings Technology. 2007;201:5228-35.

[31] Bae SG, Cho YK, Moon KI, Kim SG, Kim SW. Effects of Preferred Orientation on the Tribological Behavior of the TiN and CrN Films by the CAIP. Materials Research Society. 2011;890.

[32] Bielawski M, Seo D. Residual stress development in UMS TiN coatings. Surface and Coatings Technology. 2005;200:1476-82.

[33] Gilewicz A, Warcholinski B. Tribological properties of $\mathrm{CrCN} / \mathrm{CrN}$ multilayer coatings. Tribology International. 2014;80:34-40.

[34] Ohring M. Material Science of Thin Films:Deposition and Structure: Academic Press; 1992.

[35] Cullity BD. Elements of X-Ray Diffraction: Addison-Wesley 1956; 2001.

[36] Chandra R, Kaur D, Chawla AK, Phinichka N, Barber Z. Texture development in $\mathrm{Ti}-\mathrm{Si}-\mathrm{N}$ nanocomposite thin films. Materials Science and Engineering: A. 2006;423:111-5.

[37] Bertrand G, Savall C, Meunier C. Properties of reactively RF magnetron-sputtered chromium nitride coatings. Surface and Coatings Technology. 1997;96:323-9.

[38] Sumi H, H. Inoue, M. Taguchi, Y.Sugano, H.Masuya, N. Ito, et al. Characteristics of TiN Films Sputtered under Optimized Conditions of Metallic Mode Deposition. Japanese Journal of Applied Physics. 1997;36.

[39] Chandra R, Chawla AK, Kaur D, Ayyub P. Structural, optical and electronic properties of nanocrystalline TiN films. Nanotechnology. 2005;16:3053. 
[40] Ong H, Zhu A, Du G. Dependence of the excitonic transition energies and mosaicity on residual strain in $\mathrm{ZnO}$ thin films. Applied Physics Letters. 2002;80:941-3.

[41] Singh P, Kaur D. Influence of film thickness on texture and electrical and optical properties of room temperature deposited nanocrystalline V 205 thin films. Journal of Applied Physics. 2008;103:043507.

[42] Chawla V, Jayaganthan R, Chawla A, Chandra R. Microstructural characterizations of magnetron sputtered $\mathrm{Ti}$ films on glass substrate. Journal of Materials Processing Technology. 2009;209:3444-51.

[43] Oh U, Je JH. Effects of strain energy on the preferred orientation of TiN thin films. J Appl Phys. 1993;74:1692-6.

[44] Khamseh S, Araghi H. A study of the oxidation behavior of $\mathrm{CrN}$ and $\mathrm{CrZrN}$ ceramic thin films prepared in a magnetron sputtering system. Ceramics International. 2016;42:9988-94.

[45] Jung MJ, Nam KH, Jung YM, Han JG. Nucleation and growth behavior of chromium nitride film deposited on various substrates by magnetron sputtering. Surface and Coatings Technology. 2003;171:59-64.

[46] Mandrino D, Podgornik B. XPS investigations of tribofilms formed on CrN coatings. Applied Surface Science. 2017;396:554-9.

[47] Behrisch R, Wittmaack K. Sputtering by particle bombardment: Springer Berlin; 1981.

[48] Castaldi L, Kurapov D, Reiter A, Shklover V, Schwaller P, Patscheider J. High temperature phase changes and oxidation behavior of $\mathrm{Cr}-\mathrm{Si}-\mathrm{N}$ coatings. Surface and Coatings Technology. 2007;202:781-5. 